\title{
Solving Linear Volterra - Fredholm Integral Equation of the Second Type Using Linear Programming Method
}

Iman A. Dhari

Najwa R. Mustafa

Muna M. Mustafa*

Received 22/5/2019, Accepted 16/9/2019, Published 18/3/2020

This work is licensed under a Creative Commons Attribution 4.0 International License.

\begin{abstract}
:
In this paper, a new technique is offered for solving three types of linear integral equations of the $2^{\text {nd }}$ kind including Volterra-Fredholm integral equations (LVFIE) (as a general case), Volterra integral equations (LVIE) and Fredholm integral equations (LFIE) (as special cases). The new technique depends on approximating the solution to a polynomial of degree $(m-1)$ and therefore reducing the problem to a linear programming problem(LPP), which will be solved to find the approximate solution of LVFIE. Moreover, quadrature methods including trapezoidal rule (TR), Simpson 1/3 rule (SR), Boole rule (BR), and Romberg integration formula (RI) are used to approximate the integrals that exist in LVFIE. Also, a comparison between those methods is produced. Finally, for more explanation, an algorithm is proposed and applied for testing examples to illustrate the effectiveness of the new technique.
\end{abstract}

Keywords: Linear Volterra-Fredholm integral equation of the $2^{\text {nd }}$ kind (LVFIE), Linear programming problem (LPP), Quadrature methods.

\section{Introduction:}

Integral equations occur naturally in many fields of mechanics and mathematical physics. They also arise as representation formulas for the solutions of differential equations (1).

From the last few years, there has been interest to use the linear and nonlinear programming methods to find a numerical or approximate solution for integral equations. AL-Nasir in 1999 used the linear programming method to find numerical solution of Volterra integral equations of the $2^{\text {nd }}$ kind (2). Also, Saed in 1999 used linear programming method to find numerical solution of Fredholm integral equations of the $1^{\text {st }}$ kind (3). While Kalwi in 1999 used the same procedure to find numerical solution for Fredholm integral equations of the $2^{\text {nd }}$ kind (4). Shua"a in 2005 calculated numerical solution for Volterra integral equation using linear programming problem (5). Kamyad et al. in 2010 proposed a new approach for solving linear and nonlinear Volterra integral equations of the $1^{\text {st }}$ and $2^{\text {nd }}$ kinds first by defining a new problem in calculus of variations, which is equivalent to this kind of problem, then by using the Department of Mathematics, College of Science for Women, University of Baghdad, Baghdad-Iraq

*Corresponding

author: munamm_math@csw.uobaghdad.edu.iq

*ORCID ID: 0000-0001-8620-4976 optimal solution of the latest problem as an approximate one with a controllable error for the original solution is obtained (6). Nazemi and Farahi in 2011 considered a numerical method for nonlinear Fredholm integral equations of the second kind with the continuous kernel by converting the integral equation problem into an optimization problem (7). Skandari et al. in 2011 proposed a new approach for a class of optimal control problems to solve Volterra integral equations which is based on linear combination property of intervals (8). Erfanian and Mostahsan in 2011 considered two stages of approximation to find an approximate solution for a class of nonlinear Volterra integral equations by: first convert the integral equation to a moment problem, and then modify the new problem to two classes of optimization problems (nonconstraint optimization and optimal control problems) (9). Effati and Skandari in 2012 presented a new approach for linear Volterra integral equations based on optimal control theory and some optimal control problems corresponding Volterra integral equation are introduced which solved by discretization methods and linear programming approaches (10).

Many authors have paid attention for studying the numerical solution of LVFIE. Ahmed in 2011 investigated the numerical solution for a mixed linear Volterra-Fredholm integral equation by 
approximating the unknown function using a tensor product (Algebraic or Chebyshev)-surface and substituting it in the Volterra-Fredholm integral equations, second apply least-square technique for minimizing the error terms on the given domain, and then obtain a system of linear algebraic equations which solved using control points (11). Chen and Jiang in 2012 used Taylor expansion method to solve a mixed linear Volterra-Fredholm integral equation of the $2^{\text {nd }}$ kind (12). Ghanim in 2014 introduced numerical algorithms to find numerical solution for linear Volterra - Fredholm integral equation of the $2^{\text {nd }}$ kind using three different kinds of Lagrange polynomials (13). Mustafa and Harbi in 2014 used non-polynomial spline function to find numerical solution for Volterra integral equation of the $2^{\text {nd }}$ kind (14). Nemati et al. in 2015 proposed numerical solution of linear mixed Volterra-Fredholm integral equations in one space variable, the proposed numerical algorithm combines the trapezoidal rule, for the integration in time, with piecewise polynomial approximation, for the space discretization (15). Chniti and Alhazmi in 2015 presented smoothing transformation, Legendre and Chebyshev collocation method to solve numerically the Volterra-Fredholm integral equations with logarithmic kernel (16). Khan et al. in 2017 provided a numerical technique for obtaining approximate solution of mixed Volterra-Fredholm integral equations of $2^{\text {nd }}$ kind based on the Bernstein's approximation (17). Hasan et al. in 2017 proposed a fixed point method to solve a system of LVFIE of the $2^{\text {nd }}$ kind using fixed point method (18).

In this paper, LVFIE of the $2^{\text {nd }}$ kind of the following form are considered:

$g(x)=$

$f(x)+\int_{\mathrm{a}}^{x} w_{1}(x, t) g(t) d t+\int_{a}^{b} w_{2}(x, t) g(t) d t$

,$x \in[a, b] \ldots$ (1)

where $g(x)$ is the unknown function to be determined, $\quad f(x), w_{1}(x, t)$ and $w_{2}(x, t)$ are continuous known functions. Therefore an approximate solution depending on a polynomial of degree $(m-1)$ is proposed, which has the form:

$g(x) \approx g_{m}(x)=\sum_{i=1}^{m} c_{i} x^{i-1}$

where $c_{1}, c_{2}, \ldots, c_{m}$ are arbitrary constants to be determined. Next using numerical integration includes (TR, SR, BR, and RI) to find an approximate solution for the integral parts in Eq.1, after that using LPP to find an approximate solution to this problem. This paper is well ordered as follows: section (2) includes basic definitions, section (3) contains transforms Eq.1 to the LPP, in section (4), the algorithm for solving LVFIE is proposed, section (5) includes test examples.
Finally, section (6) gives conclusions and recommendations.

\section{Basic Definitions:}

Definition 1: An integral equation can be recognized as equations in which the indefinite function $g(x)$ to be specific appear under the integral sign. A standard formula of an integral equation in $g(x)$ is:

$$
\begin{gathered}
c(x) g(x)=f(x)+\lambda \int_{a(x)}^{b(x)} w(x, t) g(t) d t \quad, x \in \\
{[a(x), b(x)] \quad \ldots \quad(3)}
\end{gathered}
$$

where $c(x), f(x)$ and $w(x, t)$ are given continuous functions, $w(x, t)$ is known as the kernel of the integral Eq. 3, and $a(x)$ and $b(x)$ are the limits of integration, $\lambda$ is a constant parameter (19). Also, Eq. 3 is called 'Volterra integral equation' (VIE), if $b(x)$ $=x$ and $a(x)=a$, and it is called 'Fredholm integral equation' (FIE), if $b(x)=b$ and $a(x)=a$, where $a$ and $b$ are constants.

Note that, for Eq. 1 when $w_{1}(x, t)$ is equal to zero Eq. 1 becomes FIE, furthermore when $w_{2}(x, t)$ is equal to zero Eq. 1 becomes VIE. And it is called VFIE if the both integral appear at one time. In this paper Eq. 1 is taken as a general form to improve that the proposed method is effective for the three kinds of equations.

Definition 2: The general form for LPP can be expressed mathematically as follows (20):

$$
\left.\begin{array}{lr}
\text { minimize or maximize } & \mathrm{z}=\sum_{j=1}^{n} c_{j} x_{j} \\
\text { Subject to } & \\
\begin{array}{ll}
\sum_{j=1}^{n} a_{i j} x_{j}(\leq,=, \geq) b_{i}, & i=1,2, \ldots, m \\
x_{j} \geq 0, & j=1,2, \ldots, n
\end{array}
\end{array}\right\}
$$

where $c_{j}(j=1, \ldots, n)$ are real number called cost coefficients, $b_{i}(i=1, \ldots, m)$ are real number called stipulations, $\quad a_{i j}(i=1,2, \ldots, m ; j=$ $1,2, \ldots, n)$ are constants called structural coefficients and $x_{j}{ }^{\prime} s$ are called decision variables for $(j=$ $1,2, \ldots, n)$.

\section{Transform the LVFIE's of the $2^{\text {nd }}$ Kind to LPP:}

The solution of LVFIE of the $2^{\text {nd }}$ kind can be founded by substituting $g_{m}(x)$ in the Eq. 2 instead of the unknown function in Eq. 1 yields:

$\sum_{i=1}^{m} c_{i} x^{i-1}=$

$f(x)+\int_{\mathrm{a}}^{x} w_{1}(x, t) \sum_{i=1}^{m} c_{i} t^{i-1} d t+$

$\int_{a}^{b} w_{2}(x, t) \sum_{i=1}^{m} c_{i} t^{i-1} d t+\epsilon(x)$

where $\epsilon(x)$ is the approximate error, then we get:

$\epsilon(x)=$

$f(x)-\sum_{i=1}^{m} c_{i} x^{i-1}+\int_{\mathrm{a}}^{x} w_{1}(x, t) \sum_{i=1}^{m} c_{i} t^{i-1} d t+$ $\int_{a}^{b} w_{2}(x, t) \sum_{i=1}^{m} c_{i} t^{i-1} d t \quad \ldots \quad$ (5)

Simplification of Eq. 5, to obtain: 
$\epsilon(x)=$

$f(x)-\sum_{i=1}^{m} c_{i}\left[x^{i-1}-\int_{\mathrm{a}}^{x} w_{1}(x, t) t^{i-1} d t-\right.$

$\left.\int_{a}^{b} w_{2}(x, t) t^{i-1} d t\right] \ldots$

Suppose

$$
\begin{gathered}
\psi_{i}(x)=x^{i-1}-\int_{\mathrm{a}}^{x} w_{1}(x, t) t^{i-1} d t- \\
\int_{a}^{b} w_{2}(x, t) t^{i-1} d t, i=1,2, \ldots, m \ldots
\end{gathered}
$$

Now, substituting Eq. 7 in Eq. 6 yields:

$\epsilon(x)=f(x)-\sum_{i=1}^{m} c_{i} \psi_{i}(x) \quad \ldots$

and dividing the interval $[a, b]$ into $n$ subintervals to get the points $x_{j}=a+(j-1) * h, j=$ $1,2, \ldots, n+1$ where $h=\frac{b-a}{n}, x_{1}=a$, and $x_{n+1}=$ $b$. Hence, after substituting $x=x_{j}$, for $j=$ $1,2, \ldots, n+1$ in Eq. 7 , the following formula is obtained:

$\boldsymbol{\psi}_{i}\left(\boldsymbol{x}_{j}\right)=$

$\int x_{j}^{i-1}-\int_{\mathrm{a}}^{b} w_{1}\left(x_{j}, t\right) t^{i-1} d t$

if $i=1$

$\left\{x_{j}^{i-1}-\int_{a}^{x_{j}} w_{1}\left(x_{j}, t\right) t^{i-1} d t-\int_{a}^{b} w_{2}\left(x_{j}, t\right) t^{i-1} d t \quad\right.$ if $2 \leq i \leq m$

$$
j=1,2, \ldots, n+1
$$

Therefore, substituting $x=x_{j}$ for $j=1,2, \ldots, n+$ 1, Eq. 8 becomes:

$\epsilon\left(x_{j}\right)=f\left(x_{j}\right)-\sum_{i=1}^{m} c_{i} \psi_{i}\left(x_{j}\right), \quad j=1,2, \ldots, n+1$ ...(10)

Now, define $\gamma$ as:

$\gamma=\sum_{j=1}^{n+1} \epsilon\left(x_{j}\right)$

Therefore, Eq. 1 can be written in the following LPP form:

$$
\begin{aligned}
& \quad \min \gamma=\sum_{j=1}^{n+1} \epsilon\left(x_{j}\right) \\
& \text { s.t } \\
& \quad \sum_{i=1}^{m} c_{i} \psi_{i}\left(x_{j}\right)-\gamma \leq f\left(x_{j}\right) \\
& \left.\quad-\sum_{i=1}^{m} c_{i} \psi_{i}\left(x_{j}\right)-\gamma \leq-f\left(x_{j}\right)\right\}_{, j}=1, \ldots, n+1
\end{aligned} \text {...(12) }
$$

where $c_{i}$ 's are unrestricted in sign, $\psi_{i}\left(x_{j}\right)$ 's can be estimated numerically as shown in the following subsection. Hence, the values of $c_{i}$ 's are used to get the approximate solution $g_{m}(x)$ in Eq. 2, which is the approximate solution of LVFIE of the $2^{\text {nd }}$ kind [i.e. Eq. 1].

\section{Calculate $\psi_{i}\left(x_{j}\right)$ Using Numerical Integration Formulas:}

In this subsection, the numerical computation of the integral part in $\psi_{i}\left(x_{j}\right)$ is shown using quadrature methods including (TR, SR, BR, and RI). For this purpose, the following notation is used: $\int_{a_{1}}^{b_{1}} w\left(x_{j}, t\right) t^{i-1} d t$ for denotation of the integral part in $\psi_{i}\left(x_{j}\right), j=1,2, \ldots, n+1$.

Suppose $a_{1}=t_{1}<t_{2}<\cdots<t_{n}=b_{1}, t_{k}=t_{1}+$ $(k-1) h, k=1,2, \ldots, n+1$, and $h=\frac{b_{1}-a_{1}}{\mathrm{n}}$

1. Using TR: $\int_{a_{1}}^{b_{1}} w\left(x_{j}, t\right) t^{i-1} d t=\frac{h}{2}\left[w\left(x_{j}, a_{1}\right) a_{1}^{i-1}+\right.$

$\left.2 \sum_{k=2}^{n} w\left(x_{j}, t_{k}\right) t_{k}^{i-1}+w\left(x_{j}, b_{1}\right) b_{1}^{i-1}\right]$

2. Using SR:

$\int_{a_{1}}^{b_{1}} w\left(x_{j}, t\right) t^{i-1} d t=\frac{h}{3}\left[w\left(x_{j}, a_{1}\right) a_{1}^{i-1}+\right.$

$4 w\left(x_{j}, t_{2}\right) t_{2}^{i-1}+2 w\left(x_{j}, t_{3}\right) t_{3}^{i-1}+4 w\left(x_{j}, t_{4}\right) t_{4}^{i-1}+$

$\left.\ldots+4 w\left(x_{j}, t_{n}\right) t_{n}^{i-1}+w\left(x_{j}, b_{1}\right) b_{1}^{i-1}\right]$

3. Using BR:

$\int_{a_{1}}^{b_{1}} w\left(x_{j}, t\right) t^{i-1} d t=\frac{2 h}{45}\left[7 w\left(x_{j}, a_{1}\right) a_{1}^{i-1}+\right.$

$32 w\left(x_{j}, t_{2}\right) t_{2}^{i-1}+12 w\left(x_{j}, t_{3}\right) t_{3}^{i-1}+$

$32 w\left(x_{j}, t_{4}\right) t_{4}^{i-1}+$

$14 w\left(x_{j}, t_{5}\right) t_{5}^{i-1}+\cdots+32 w\left(x_{j}, t_{n}\right) t_{n}^{i-1}+$

$\left.7 w\left(x_{j}, b_{1}\right) b_{1}^{i-1}\right]$

4. Using RI:

$\int_{a_{1}}^{b_{1}} w\left(x_{j}, t\right) t^{i-1} d t=\frac{h}{2}\left[w\left(x_{j}, a_{1}\right) a_{1}^{i-1}+\right.$ $2 \sum_{k=2}^{2^{j}-1} w\left(a_{1}+(2 k-1) * h_{j}, t_{k}\right) t_{k}^{i-1}+$

$\left.w\left(x_{j}, b_{1}\right) b_{1}^{i-1}\right] \ldots$

The Algorithm for Solving LVFIE of the $2^{\text {nd }}$ kind:

The following steps are used to find an approximate solution of LVFIE of the $2^{\text {nd }}$ kind:

Step 1. Select two positive integers $m$ and $n$, (where $m$ represent the number of terms of series in Eq. 2, $n$ represent the number of subinterval for the closed interval $[\mathrm{a}, \mathrm{b}])$.

Step 2. Calculate $f\left(x_{j}\right), \quad j=1: n+1$.

Step 3. Using numerical integration to calculate $\psi_{i}\left(x_{j}\right)$ in Eq. 8 for each $i=1,2, \ldots, m ; j=$ $1,2, \ldots, n+1$, which are (TR, SR, BR, and RI).

i. TR, by using Eq. 13.

ii. SR, by using Eq. 14 .

iii. BR, by using Eq. 15 .

iv. RI, by using Eq. 16 .

Step 4. Compute $\gamma$ from Eq. 11.

Step 5. Construct the LP model Eq. 12.

Step 6. Using generalized simplex method to find the optimal approximation of $c_{i}, i=1,2, \ldots, m$.

Step 7. Determine the approximate solution of Eq. 1 by substituting the values of $c_{i}, i=1,2, \ldots, m$ in Eq. 2.

Note that in this paper MATLAB R2018a is used for implementation of the algorithm.

\section{Numerical Test Examples:}

In this section, some of the numerical test examples are given to illustrate the proposed method for solving the LVFIE of the $2^{\text {nd }}$ kind. In all the test examples $g(x)$ is chosen in such a way that we know the exact solution. The exact solution is used only to show that the numerical solution obtained with our method is true. Then, in these test 
examples the absolute error are calculated in all points.

Test Example 1: Consider the LVFIE of $2^{\text {nd }}$ kind (17):

$$
g(x)=x-2 e^{x}+e^{-x}+1+\int_{0}^{x} t e^{x} g(t) d t+\int_{0}^{1} e^{x+t} g(t) d t
$$

for which the exact solution is $g(x)=e^{-x}$. Table 1 shows the absolute error obtained by using (TR, SR, $\mathrm{BR}$, and RI) for $h=0.1, n=10, m=10$, where $m$ is the degree of approximate polynomial $g(x)$ appear in Eq. 2 and $\|e r r\|_{\infty}$ is the maximum absolute error, for $x \in[0,1]$.

Table 1. The absolute error of test example 1

\begin{tabular}{ccccc}
\hline $\boldsymbol{x}$ & Error using TR & Error using SR & Error using BR & Error using RI \\
\hline 0 & 0.000102493241609158 & $2.49109375349832 \mathrm{e}-08$ & $2.01430538915304 \mathrm{e}-10$ & $2.27079022252497 \mathrm{e}-10$ \\
0.1 & 0.000113451577860246 & $2.77139680093796 \mathrm{e}-08$ & $1.86916038202867 \mathrm{e}-10$ & $2.15425566274519 \mathrm{e}-10$ \\
0.2 & 0.000124537294404647 & $3.11356900262183 \mathrm{e}-08$ & $1.98265071027492 \mathrm{e}-10$ & $2.30316765659211 \mathrm{e}-10$ \\
0.3 & 0.000133715127830891 & $3.68140724571475 \mathrm{e}-08$ & $1.37722810933383 \mathrm{e}-09$ & $1.34068800505815 \mathrm{e}-09$ \\
0.4 & 0.000138651792887523 & $3.9765073456266 \mathrm{e}-08$ & $1.18836496199037 \mathrm{e}-10$ & $1.60952806638193 \mathrm{e}-10$ \\
0.5 & 0.00013651617237409 & $4.35975450185921 \mathrm{e}-08$ & $1.32601707392155 \mathrm{e}-10$ & $1.81023751544274 \mathrm{e}-10$ \\
0.6 & 0.000123448433075213 & $4.56720178343417 \mathrm{e}-08$ & $7.85884357590305 \mathrm{e}-10$ & $7.32290228455668 \mathrm{e}-10$ \\
0.7 & $9.37002095329209 \mathrm{e}-05$ & $3.9269196672187 \mathrm{e}-08$ & $1.74255054830041 \mathrm{e}-11$ & $6.94454493910257 \mathrm{e}-11$ \\
0.8 & $3.80499682491875 \mathrm{e}-05$ & $1.93316483931838 \mathrm{e}-08$ & $7.09133862741851 \mathrm{e}-11$ & $1.00750630060986 \mathrm{e}-10$ \\
0.9 & $5.94811463363598 \mathrm{e}-05$ & $2.88283432681169 \mathrm{e}-08$ & $7.03646030331129 \mathrm{e}-11$ & $2.69834155020021 \mathrm{e}-11$ \\
1 & 0.000228347336972523 & $1.32361363092137 \mathrm{e}-07$ & $6.38649244599776 \mathrm{e}-10$ & $4.09659972611109 \mathrm{e}-10$ \\
$\|\mathrm{err}\|_{\infty}$ & 0.000228347336972523 & $1.32361363092137 \mathrm{e}-07$ & $1.37722810933383 \mathrm{e}-09$ & $1.34068800505815 \mathrm{e}-09$ \\
\hline
\end{tabular}

Table 2 shows the maximum absolute error of test example 1 by using RI with 10 columns for $, n=5,10, \ldots, 30 \quad$ and $\quad m=5,10, \ldots, 20 \quad$ and comparing with the minimum error in (17) obtained using Bernstein polynomials.

Table 2. Maximum absolute error by using RI with 10 columns

\begin{tabular}{cccccc}
\hline & $\mathbf{m}=\mathbf{5}$ & $\mathbf{m = 1 0}$ & $\mathbf{m = 1 5}$ & $\mathbf{m = 2 0}$ & $\begin{array}{c}\text { Minimum } \\
\text { error in (17) }\end{array}$ \\
\hline $\mathrm{n}=5$ & $1.80466052200901 \mathrm{e}-05$ & $1.73236324783055 \mathrm{e}-05$ & 0.000139531997039199 & 0.00048852860377735 & \\
$\mathrm{n}=10$ & $1.29375330428783 \mathrm{e}-05$ & $1.34068800505815 \mathrm{e}-09$ & $2.30496499664667 \mathrm{e}-09$ & $2.08972145032682 \mathrm{e}-07$ & \\
$\mathrm{n}=15$ & $1.2817840279622 \mathrm{e}-05$ & $1.83188264557543 \mathrm{e}-09$ & $5.94055804548077 \mathrm{e}-10$ & $3.00607217784687 \mathrm{e}-07$ & $\mathbf{7 . 0 7 1 0 6 7 8 1 2} *$ \\
$\mathrm{n}=20$ & $1.17171123399373 \mathrm{e}-05$ & $1.86609017127637 \mathrm{e}-09$ & $4.58927396085329 \mathrm{e}-09$ & $1.19387566610563 \mathrm{e}-07$ & $\mathbf{1 0}$ \\
$\mathrm{n}=25$ & $1.12564382384051 \mathrm{e}-05$ & $2.68936872771519 \mathrm{e}-09$ & $3.24708193666368 \mathrm{e}-09$ & $1.97195315632115 \mathrm{e}-09$ & \\
$\mathrm{n}=30$ & $1.11584049335978 \mathrm{e}-05$ & $1.78146986051786 \mathrm{e}-09$ & $5.00741970110852 \mathrm{e}-09$ & $1.49425165574257 \mathrm{e}-08$ & \\
\hline
\end{tabular}

Test Example 2: Consider the FIE of the $2^{\text {nd }}$ kind (21): $g(x)=\sin (x)-x+\int_{0}^{\pi / 2} x \operatorname{tg}(t) d t$ for which the exact solution is $g(x)=\sin (x)$.
Table 3 shows the absolute error obtained by using (TR, SR, BR, and RI) for $h=0.1, n=10, m=10$, and $x \in\left[0, \frac{\pi}{2}\right]$.

Table 3. The absolute error of test example 2

\begin{tabular}{ccccc}
\hline $\boldsymbol{x}$ & Error using TR & Error using SR & Error using BR & Error using RI \\
\hline 0 & 0 & 0 & 0 & 0 \\
$\frac{\pi}{20}$ & 0.000275096664244356 & $3.46922592708854 \mathrm{e}-07$ & $3.93723234570764 \mathrm{e}-09$ & $5.28284549439206 \mathrm{e}-09$ \\
$\frac{2 \pi}{20}$ & 0.000550193328488546 & $6.84035879827682 \mathrm{e}-07$ & $1.93483751242951 \mathrm{e}-09$ & $7.5638911800624 \mathrm{e}-10$ \\
$\frac{3 \pi}{20}$ & 0.000825955324154082 & $1.0238570866683 \mathrm{e}-06$ & $5.09898773204398 \mathrm{e}-09$ & $1.06214725903442 \mathrm{e}-09$ \\
$\frac{4 \pi}{20}$ & 0.00110038665697776 & $1.3680717573239 \mathrm{e}-06$ & $3.86967580201514 \mathrm{e}-09$ & $1.51277890214629 \mathrm{e}-09$ \\
$\frac{5 \pi}{20}$ & 0.00137482378285103 & $1.7118563248042 \mathrm{e}-06$ & $3.070467546884 \mathrm{e}-09$ & $3.65760144394045 \mathrm{e}-09$ \\
$\frac{6 \pi}{20}$ & 0.00165057998546692 & $2.05210763648545 \mathrm{e}-06$ & $5.80451475773458 \mathrm{e}-09$ & $2.26916840873059 \mathrm{e}-09$ \\
$\frac{7 \pi}{20}$ & 0.00192639040596387 & $2.39212967390046 \mathrm{e}-06$ & $8.76783445846741 \mathrm{e}-09$ & $6.5146210648237 \mathrm{e}-10$ \\
$\frac{8 \pi}{20}$ & 0.00220077331395585 & $2.73614351353757 \mathrm{e}-06$ & $7.73935204811949 \mathrm{e}-09$ & $3.02555758224798 \mathrm{e}-09$ \\
$\frac{9 \pi}{20}$ & 0.00247586997820104 & $3.07816145295181 \mathrm{e}-06$ & $8.70677108189 \mathrm{e}-09$ & $3.40375128082826 \mathrm{e}-09$ \\
$\frac{\pi}{2}$ & 0.00275024709314409 & $3.41770074263614 \mathrm{e}-06$ & $1.21528355156997 \mathrm{e}-08$ & $1.30330013448088 \mathrm{e}-09$ \\
$\|$ err 09 & 0.00275024709314409 & $3.41770074263614 \mathrm{e}-06$ & $1.21528355156997 \mathrm{e}-08$ & $5.28284549439206 \mathrm{e}-09$ \\
\hline
\end{tabular}


Table 4 shows the maximum absolute error of test example 2 by using RI with 10 columns for $, n=5,10, \ldots, 30 \quad$ and $\quad m=5,10, \ldots, 20 \quad$ and comparing with the minimum error in (21) using A wavelet based method.

Table 4. Maximum absolute error of test example 2

\begin{tabular}{cccccc}
\hline & $\mathbf{m}=\mathbf{5}$ & $\mathbf{m}=\mathbf{1 0}$ & $\mathbf{m = 1 5}$ & $\mathbf{m = 2 0}$ & $\begin{array}{c}\text { Minimum } \\
\text { error in }(\mathbf{2 1})\end{array}$ \\
\hline $\mathrm{n}=5$ & 0.000250532304200357 & 0.00204524171715315 & 0.00700937506399091 & 0.00299344393818657 & $\mathbf{4 . 8 7 0 5 1} * \mathbf{1 0}{ }^{-7}$ \\
$\mathrm{n}=10$ & 0.000150493052866185 & $5.28284549439206 \mathrm{e}-09$ & $2.95809066130914 \mathrm{e}-09$ & $1.36430372665863 \mathrm{e}-07$ & \\
$\mathrm{n}=15$ & 0.000126432937772925 & $1.25692456443005 \mathrm{e}-10$ & $3.26260370886455 \mathrm{e}-07$ & $2.07978079203031 \mathrm{e}-12$ & \\
$\mathrm{n}=20$ & 0.000122723915813472 & $9.42873719211867 \mathrm{e}-07$ & $5.11214459653075 \mathrm{e}-09$ & $7.28038746622417 \mathrm{e}-07$ & \\
$\mathrm{n}=25$ & 0.000134526659284484 & $1.53481720666093 \mathrm{e}-08$ & $3.21489566856847 \mathrm{e}-07$ & $5.01681764353279 \mathrm{e}-07$ & \\
$\mathrm{n}=30$ & 0.000130829048964776 & $7.12419012671717 \mathrm{e}-11$ & $3.28022662254845 \mathrm{e}-07$ & $6.90780765921772 \mathrm{e}-13$ & \\
\hline
\end{tabular}

Test Example 3: Consider the VIE of the $2^{\text {nd }}$ kind. (22)

$g(x)=x^{5}-\frac{x^{8}}{7}+\int_{0}^{x} x \operatorname{tg}(t) d t$ for which the exact solution is $g(x)=x^{5}$. Table 5 shows the absolute error obtained by using (TR, SR, BR, and RI) for $h=0.1, n=10, m=10$, and $x \in[0,1]$.

Table 5: The absolute error of test example 3

\begin{tabular}{ccccc}
\hline $\boldsymbol{x}$ & Error using TR & Error using SR & Error using BR & Error using RI \\
\hline 0 & 0 & 0 & 0 & 0 \\
0.1 & $4.07240313671209 \mathrm{e}-08$ & $8.24038275934354 \mathrm{e}-08$ & $4.7171878984503 \mathrm{e}-10$ & $3.3881317890172 \mathrm{e}-21$ \\
0.2 & $5.14835299653517 \mathrm{e}-08$ & $1.63159514236203 \mathrm{e}-07$ & $9.34002835088679 \mathrm{e}-10$ & $1.0842021724855 \mathrm{e}-19$ \\
0.3 & $1.0280117092613 \mathrm{e}-07$ & $2.34026355174985 \mathrm{e}-07$ & $1.33967841290869 \mathrm{e}-09$ & $8.67361737988404 \mathrm{e}-19$ \\
0.4 & $8.117302906889 \mathrm{e}-07$ & $2.73578518049725 \mathrm{e}-07$ & $1.56609384314998 \mathrm{e}-09$ & $3.46944695195361 \mathrm{e}-18$ \\
0.5 & $4.94217156043336 \mathrm{e}-06$ & $2.40612479093794 \mathrm{e}-07$ & $1.37738051173009 \mathrm{e}-09$ & $1.38777878078145 \mathrm{e}-17$ \\
0.6 & $2.14923150374663 \mathrm{e}-05$ & $6.75544593181643 \mathrm{e}-08$ & $3.86713883138157 \mathrm{e}-10$ & $2.77555756156289 \mathrm{e}-17$ \\
0.7 & $7.45893556647337 \mathrm{e}-05$ & $3.46132139256161 \mathrm{e}-07$ & $1.98142546814495 \mathrm{e}-09$ & $5.55111512312578 \mathrm{e}-17$ \\
0.8 & 0.000220789721384063 & $1.1405392973951 \mathrm{e}-06$ & $6.52899079245373 \mathrm{e}-09$ & $1.11022302462516 \mathrm{e}-16$ \\
0.9 & 0.000579980666897018 & $2.50190694273122 \mathrm{e}-06$ & $1.43221082771205 \mathrm{e}-08$ & $3.33066907387547 \mathrm{e}-16$ \\
1 & 0.0013869622275107 & $4.66921551289801 \mathrm{e}-06$ & $2.6728815827326 \mathrm{e}-08$ & $4.44089209850063 \mathrm{e}-16$ \\
$\|\operatorname{err}\|_{\infty}$ & 0.00138699622275107 & $4.66921551289801 \mathrm{e}-06$ & $2.6728815827326 \mathrm{e}-08$ & $4.44089209850063 \mathrm{e}-16$ \\
\hline
\end{tabular}

Table 6 shows the maximum absolute error of test example 3 by using RI with 10 columns with $, n=5,10, \ldots, 30 \quad$ and $m=5,10, \ldots, 20$ and comparing with the minimum error in (22) using analytical techniques for a numerical solution.

Table 6. Maximum absolute error of test example 3

\begin{tabular}{cccccc}
\hline & $\mathbf{m}=\mathbf{5}$ & $\mathbf{m = 1 0}$ & $\mathbf{m = 1 5}$ & $\mathbf{m = 2 0}$ & $\begin{array}{c}\text { Minimum } \\
\text { error in }(\mathbf{2 2})\end{array}$ \\
\hline $\mathrm{n}=5$ & 0.00344432832521402 & $3.33066907387547 \mathrm{e}-16$ & 0.00859839736540469 & 0.0236481084743722 & $\mathbf{4 . 6 3 * 1 0}$ \\
$\mathrm{n}=10$ & 0.00210910706319622 & $4.44089209850063 \mathrm{e}-16$ & $1.01918473660589 \mathrm{e}-13$ & $2.28582959427293 \mathrm{e}-06$ & \\
$\mathrm{n}=15$ & 0.00219352883926544 & $8.21565038222616 \mathrm{e}-15$ & $5.77315972805081 \mathrm{e}-15$ & $4.37383462781327 \mathrm{e}-12$ & \\
$\mathrm{n}=20$ & 0.00203247879180546 & $1.38222766565832 \mathrm{e}-13$ & $7.21644966006352 \mathrm{e}-15$ & $1.09923181668137 \mathrm{e}-12$ & \\
$\mathrm{n}=25$ & 0.00206776701090695 & $7.105427357601 \mathrm{e}-14$ & $7.7715611723761 \mathrm{e}-15$ & $5.313527395856 \mathrm{e}-13$ & \\
$\mathrm{n}=30$ & 0.00199598890700549 & $3.84636766881385 \mathrm{e}-13$ & $5.46229728115577 \mathrm{e}-14$ & $4.3310910413652 \mathrm{e}-12$ & \\
\hline
\end{tabular}

\section{Conclusions:}

This paper presents a method of finding the solution of LVFIE of the $2^{\text {nd }}$ kind using the LPP. The polynomial of degree $m-1$ is used to convert the LVFIE of the $2^{\text {nd }}$ kind into LPP. TR, SR, BR and RI are proposed for computing the integral part and the comparison between those methods is made. The accuracy of the method has been shown by applying different test examples and comparing the results with the exact solution. The results for the LPP are improved using RI instead of the other methods to evaluate the integrals within linear programming method. Also, it is supposed that the best result can be obtained by increasing both the number of basic functions $(m)$ and the number of constraints (n) with keeping $(n>m)$. For future work, we suggest using this method for solving 'Volterra- Fredholm integro-differential equations', by using suitable approximation for derivatives part.

\section{Conflicts of Interest: None.}




\section{References:}

1. Kanwal RP. Linear Integral Equations Theory and Techniques. New York: Academic Press, INC.; 1971. $296 \mathrm{p}$.

2. AL-Nasir RH. Numerical Solution of Volterra Integral Equations of the Second Kind. M. Sc. Thesis. Baghdad: University of Technology; 1999.

3. Saed NS. Numerical Solution of Fredholm Integral Equations of the First Kind. M. Sc. Thesis. Baghdad: University of Technology; 1999.

4. Kalwi PM. Numerical Methods for Solving Fredholm Integral Equations of The Second Kind. M. Sc. Thesis. Baghdad: University of Technology; 1999.

5. Shua"a AH. Using Linear Programming to find solution Volterra Integral Equation. J of Col of B ED. 2005;7(43):12-31.

6. Kamyad AV, Mehrabinezhad M, Sabri-Nadjafi J. A Numerical Approach for Solving Linear and Nonlinear Volterra Integral Equations with Controlled Error. IAENG IJAM. 2010; 40(2): 69-74.

7. Nazemi AR, Farahi MH. A Numerical Scheme for Fredholm Integral Equations. JARAM. 2011; 3(1): 47-62.

8. Skandari MH, Erfanian HR, Kamyad AV. A New Approach for a Class of Optimal Control Problems of Volterra Integral Equations. ICA. 2011; 2: 121-125.

9. Erfanian HR, Mostahsan T. Approximate Solution of a Class of Nonlinear Volterra Integral Equations. J Math Computer Sci. 2011; 3(3): 278-286.

10. Effati S, Skandari MH. Optimal Control Approach for Solving Linear Volterra Integral Equations. IJISA. 2012; 4: 40-46.

11. Ahmed ShSh. Numerical Solution for VolterraFredholm Integral Equation of the Second Kind by Using Least Squares Technique. IJS. 2011; 52(4): 504-512.

12. Chen Z, Jiang W. An Approximate Solution for a Mixed Linear Volterra-Fredholm Integral Equation. App Math Lett. 2012; 25: 1131-1134.

13. Ghanim IN. Modified Numerical Algorithms for Solving Linear Volterra-Fredholm Integral Equations of the Second Kind'. M. Sc. Thesis. Baghdad: University of Baghdad; 2014.

14. Mustafa MM, Harbi SH. Solution of Second Kind Volterra Integral Equations Using Non-Polynomial Spline Functions. Baghdad Sci J. 2014; 11(2): $207-$ 210.

15. Nemati S, Lima P, Ordokhani Y. Numerical Method for the Mixed Volterra-Fredholm Integral Equations Using Hybrid Legendre Functions. In: Brandts J, Korotov S, Křížek M, Segeth K, Šístek J, Vejchodský $\mathrm{T}$, editors. Conference Applications of Mathematics, in honor of the birthday anniversaries of Ivo Babuška (90), Milan Práger (85), and Emil Vitásek (85). Prague: Institute of Mathematics AS CR; 2015: 184193.

16. Chniti Ch, Alhazmi ShA. On the Numerical Solution of Volterra-Fredholm Integral Equations with Logarithmic Kernel Using Smoothing Transformation. IJAMR. 2015; 4 (1): 183-192.

17. Khan F, Mustafa G, Omar M, Komal H. Numerical Approach Based on Bernstein Polynomials for Solving Mixed Volterra-Fredholm Integral Equations. AIP Advances. 2017; 7(12): ID 125123.

18. Hasan TI, Salleh Sh, Sulaiman NA. Fixed Point Method and its Improvement for the System of Volterra-Fredholm Integral Equations of the Second Kind. Matematika. 2017; 33(2): 191-206.

19. Wazwaz AM. Linear and Nonlinear Integral Equations Methods and Applications. Beijing: Higher Education Press and Berlin Heidelberg: SpringerVerlag; 2011. $639 \mathrm{p}$.

20. Gupta PK, Hira DS. Operation Research. $7^{\text {th }}$ Revised Edition. New Delhi: S. CHAND \& COMPANY PVT. LTD; 2014. 1498 p.

21. Lin En-Bing, Al-Jarrah Y. A Wavelet Based Method for the Solution of Fredholm Integral Equations. AJCM. 2012; 2(2): 114-117.

22. Berenguer MI, Gơmez D, Garralda-Guillem AI, Ruiz Galỏn M, Serrano Pẻrez MC. Analytical Techniques for a Numerical Solution of the Linear Volterra Integral Equation of the Second Kind. Abs Appl Anal. 2009; 2009: Article ID 149367.

\section{حل معادلة فولتيرا- فريدهولم التكاملية الخطية من النوع الثاني باستخدام طريقة البرمجة الخطية
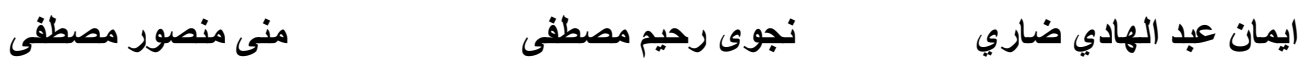 \\ قسم الرياضيات، كلية العلوم للبنات، جامعة بغداد، بغداد، العراق.}

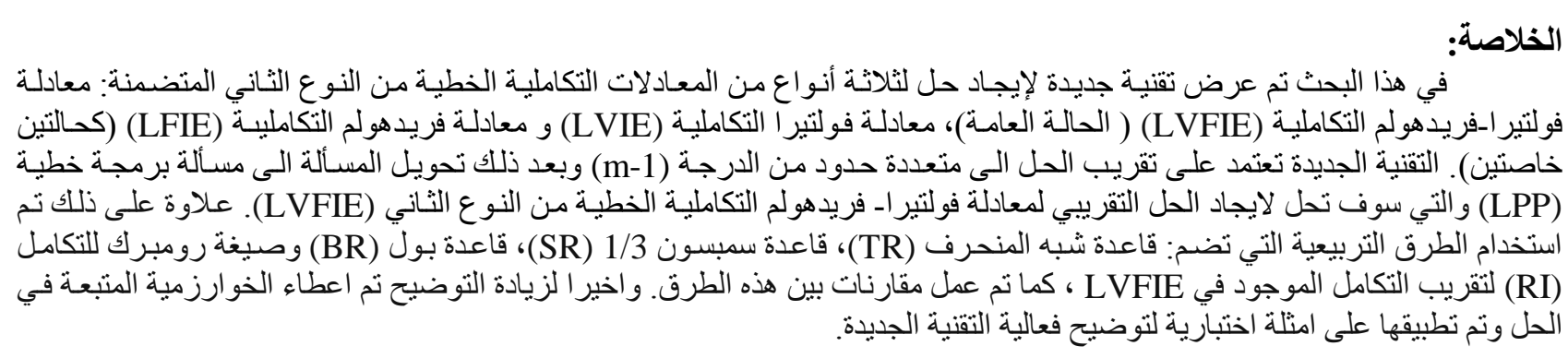

الكلمات المفتاحية: معادلة فولتير اـ فريدهولم التكاملية الخطية من النوع الثاني، مسألة البرمجة الخطية، الطرق التربيعية. 